\title{
INTER-DIVISION IV-V WORKING GROUP on Ap and Related Stars
}

\author{
CHAIR \\ PAST CHAIR \\ BOARD
}

\author{
Margarida S. Cunha \\ Werner Weiss \\ Mike Dworetsky \\ Oleg Kochukhov \\ Friedrich Kupka \\ Francis Leblanc \\ Richard Monier \\ Ernst Paunzen \\ Nikolai Piskunov \\ Hiromoto Shibahashi \\ Barry Smalley \\ Jozef Ziznovsky
}

\section{PROCEEDINGS BUSINESS SESSION, 7th of August 2009}

\section{Balance of Activities}

The business meeting started at 11h00, in the presence of 18 members, with a brief summary of the activities and achievements of the Working group during the triennium 2006-2009.

Particular emphasis was given to the work done on the renovation of the ApN newsletter (http://ams.astro.univie.ac.at/apn), by the ApN editors, Stefano Bagnulo, Luca Fossati, and Gregg Wade, to respond more adequately to the community needs. The second activity to deserve particular attention was the organization of a Wish List on atomic and molecular data, to be iterated during the next triennium in close interaction with Commission 14. Finally, the Chair reported on the main events organized by members of the Working Group, in particular the $C P \# A p$ Workshop, that took place in Vienna, Austria, in September 2007, and whose organization was led by Ernst Paunzen, and the Joint Discussion 4 Progress in understanding the physics of $A p$ and related stars, organized by the Working Group, that took place during the General Assembly.

\section{Planning of activities for the next triennium}

Following on the report by the Chair of the Working Group, there was a general discussion on specific activities to be carried out during the period 2009-2012.

No resolution was made with regards to the organization of future meetings, although the opinion of most members was that the Working Group should aim at organizing a large Symposium in the year following the next General Assembly (i.e., 2013). In the mean time, smaller meetings / workshops are expected to be organized on specific topics by members of the Working Group.

The members have also discussed the continuation of the efforts to strengthen the interaction between the Working Group and Commission 14, on Atomic and Molecular Data.

\section{New composition of the Organizing Committee}

During the Business Meeting elections were held to elect two new members for the Organizing Committee. The choice of the new Chair was postponed to a later date, having in the mean time been conducted by e-mail. The new composition of the organizing Committee is as follows: 
- New Chair: Gautier Mathys (Chile).

- Outgoing OC members: Barry Smalley (UK); Werner Weiss (Austria).

- Incoming OC members: Gautier Mathys (Chile); Olga Pintado (Argentina).

The Chair expressed her gratitude to Barry Smalley and Werner Weiss for their endless contributions to the Working Group over at least three terms, during which they were part of the Organizing Committee. Thanks were also given to all members that helped organizing the activities of the Working Group over the past three years, with particular thanks to the members of the Organizing Committee and the editors of the ApN.

Margarida S. Cunha Chair of the Working Group 